\title{
Issues of Disclosure in Relation to HIV/AIDS: Evidence from the Kwazulu Natal Province
}

\author{
N.G. Tshabalala, PhD. \\ Department of Sociology, University of Zululand, P/bag X1001, KwaDlangezwa, 3886, South Africa \\ Email: Jeffrey058@gmail.com
}

\author{
Doi:10.5901/mjss.2014.v5n20p2067
}

\begin{abstract}
The study aimed to investigate issues of disclosure in relation to HIV and AIDS. Based on the findings of the study, the researcher was able to establish an intervention programme aimed at addressing the barriers associated with HIV disclosure. Using a survey design, data was collected from a sample of 30 respondents consisting of 15 males and 15 female $(n=30)$ that were chosen from the support groups based at one of the Hospitals in KwaZulu-Natal Province. All participants were aware of their HIV status, and had received post-test counselling and had disclosed in their support groups. The results of the study also showed that the established intervention programme by the researcher would help to address the myths that are associated with HIVIAIDS. In every culture, rumours and myths exist about HIVIAIDS based on fear, denial, or misinformation. The study recommends that more research needs to be done in order to give support to people who are HIV-negative to alleviate their fears which may be interpreted as discrimination. Government needs to invest more money in HIVIAIDS research and training programmes for HIVIAIDS counsellors, medical doctors, traditional healers and the communities at large.
\end{abstract}

Keywords: HIVIAIDS, Psychology, HIV-disclosure; Counselling.

\section{Introduction}

HIVIAIDS is increasingly affecting the health and welfare of children and adults in many highly affected countries (WHO and UNICEF, 2008). Recent estimates (UNAIDS, 2010) suggest that, globally, about 2.5 million children younger than 15 years of age are infected with HIV; $90 \%$ of whom live in sub-Saharan Africa. However, with improving antiretroviral treatment in low-income countries, people affected by this HIVIAIDS are experiencing longer and better living lives (Lesch et al, 2007). Consequently, disclosure of HIV status to infected people is becoming important in stemming the spread of the disease and influencing participation in healthcare decision-making (Lesch et al, 2007). Disclosure of the diagnosis of HIV is a controversial and emotionally laden issue. The initial reaction most adults have upon learning of their own, or of a family member's, HIV status is that the diagnosis must be kept secret; this is often due to the fear of the social stigma. Although in some countries there are prescriptions regarding disclosure of status for certain categories of the populations, (i.e. school-age children, pregnant women) (Butler et al, 2009), health care workers and professionals continue to struggle with disclosure and the management of information around HIV status. For example, studies showed that $25 \%$ and $90 \%$ of school-age children with HIV infection/AIDS have not been told that they are infected (Grubman et al, 1995). As a result of this, the emotional effect of disclosure is a major task facing health care professionals. Disclosure also has an effect on disease progression and clinical management (Ferris et al, 2007) For example, infected mothers are often worried about their children learning of their illness (Armistead et al, 2001; Kirshenbaum and Nevid, 2002). There are however, benefits associated with disclosure. For example, children's knowledge of maternal HIVIAIDS status is associated with an increase in child psychosocial adjustment and self-esteem (Murphy et al, 2001).

\section{Concerns about HIV Status Disclosure}

Disclosing an HIV -positive status to others is a primary and immediate concern to those infected individuals and is often a complex and emotionally charged action. Van Wyk (1999) described two extreme responses. At one extreme, there is a desire to withdraw and isolate. On the other extreme, there is the desire to" tell the world". Neither of these extremes is adaptive .This is because disclosure can expose HIV-positive individuals to stigmatization, isolation, discrimination, and rejection by friends family and community (Ewing, 2003). Nevertheless, disclosure is an issue that all individuals face, since it is the perquisite for receipt of appropriate emotional support from others and proper health care (Derlega, et al., 2001). Support can help the individual to accept his or her status, and the stress of coping on his or her own can be reduced. Disclosure has a number of potential benefits for the individual including improved access to necessary medical 
care and increased opportunities to discuss and implement HIV risk reduction with partners, and increased opportunities to plan for the future. Lastly, it can also promote responsibility and help to reduce the stigma, discrimination and denial that is associated with HIV and AIDS.

Research conducted by Duffy (1994) suggested that disclosing an HIV-positive diagnosis to another individual may be an important contributor to one's perceived social support. The relationship between social support and disclosure may influence psychological adjustment. For example, HIV-positive individuals who share their status with a family member or their partners demonstrated significantly lower levels of emotional distress than those who chose to keep their status secrete (Armistead \& Tanenbaum, 2001). On the other hand, some researchers have suggested that disclosure of HIV-positive status may provoke violence in intimate relationships. The kind of violence that may occur can be physical or emotional, combined with verbal abuse. People living with HIV may need a great deal of support in order to deal with the issue of violence around disclosure. Culture can also provide a context within which disclosure occurs. People from different cultures may also differ in their views of disclosure. Societal norms, values and expectations about what is appropriate to reveal and not to reveal are socially learned and differ from culture to culture.

\section{Theoretical Approaches to HIVIAIDS}

Theories about the origins of HIVIAIDS are numerous and varied. Some of the most common are the following:

\subsection{The Hunter theory}

The Hunter theory is the most commonly accepted. In this perspective, the Simian (monkey) Immunodeficiency Virus (SIV) was transferred to humans as a result of chimpanzees being killed and eaten or their blood getting into cuts or wounds of the hunter. Normally, the hunter's body would have fought off SIV, but on a few occasions, it adapted itself within its new human host and became HIV-1. For example, in a sample 1099 individuals from Cameroon, it was discovered that up ten were infected with SFV (Simian Foamy Virus) (1\%), an illness like SIV, which was previously thought only to infected primates. All these infections were believed to have been acquired through the butchering and consumption of monkey and ape meat (Wolfe et al., 2004).

\subsection{The Contaminated Needle theory}

The Contaminated Needle theory is an extension of the hunter theory. For example, in the 1950's, the use of disposable plastic syringes became commonplace around the world as a cheap, sterile way to administer medicines. It is likely therefore that one single syringe would have been used to inject a number of patients without any sterilization being carried out (http //www.avert.orgins.htm).

\subsection{The Conspiracy theory}

In the conspiracy theory, some say that HIV is "man-made" while others say that HIV is a "conspiracy theory". For example, in a survey conducted in the United States, the survey identified a significant number of African Americans who believed that HIV was manufactured as part of the biological warfare programme aimed at wiping out a large number of blacks and homosexual people.

Loopholes in the aforementioned theories:

These theories fail to take into consideration the lack of genetic-engineering technology available to "create" the virus at the time that AIDS first made its appearance (htt://www.avert.org).

\section{Disclosing of HIV Status: Patterns, Reasons and Reactions}

As previously mentioned, disclosing of HIV infection can lead to important social support that can mitigate the negative effects of stress (Hays et al., 1993). Conversely, hiding one's status may not only preclude HIV-related social support and its attendant benefits but may also have direct negative effects on disease progression for HIV -positive individuals. The following are some cases of HIV infected South Africans from Lusikisiki, a rural region in the Eastern Cape Province telling their stories including how they received social support from their families:

Highlight 
"My name is Nonfumaneko. I am fifteen years old. I started to be sick in May last year (2004)."

Nofumaneko Continues....

It was said I must have an HIV test. It was positive. My heart was very painful at the news, but I did no cry. The nurses told me I must not be scared and that if I take my medication, I am going to get better.

For a while I felt stronger but now I cannot do anything. I am very weak. It is difficult for me to walk even a few steps. My sister helps me to wash. My family is supporting me. They come to sit with me every time I take my medication. I feel very happy because they show me that they really love me.

I want to go back to school when I am better, so I can learn to be a nurse. My dream is to help others.

"Last November (2004) Nomfunekiso died"

Source: Living with AIDS, Gideon, 2005

Another individual from Lusikisiki had the following to say after discovering that she was HIV-positive: Highlight

My name is NOZAMILE. I am 22 years old, and I have four children. Last year I decided to get an HIV test because I had back pains, headaches, and diarrhoea. When they told me I was HIV-positive, I was very sad. If I die, I thought, who is going to care for my children?

I phoned my husband, who works at a gold mine, to tell him this news. He then told me he was HIV-positive as well as, and was already getting ARV treatment from the mine hospital. I was very angry and asked him why he came home with such a big disease when I had small children to bring up. He said he had been afraid to tell me that he had this disease.

I decided that I wanted to have all my children tested for HIV. The AIDS counsellor took a drop of blood from their fingers and put it on a small cardboard strip. Then we had to wait 15 minutes to see how many lines appeared. Two lines mean HIV-positive, but all my children had only one line. They will be able to live healthy lives.

I have started to attend the support group at Xurana Clinic, and I like going there. Every time we open with a prayer and sing many songs. I was also part of a big church service in my village, where I was called forward for a special blessing. I was happy to receive such a blessing in front of so many people.

I have been taking ARV pills for two months now, and I am free in my heart. I can take care of my children, clean my house, look after the goats, fetch water and cook the food. I have decided to tell everybody that I have HIV. I want to live a better life, so I don't want to be hiding something like this.

Source: Living with AIDS, Gideon, 2005

\section{Highlight}

In Everyone Knows Someone Campaign by the Sunday Time News Paper which is aimed at encouraging people to know their HIV status, the following is what Dr Mangosuthu Buthelezi, President of Inkatha Freedom Party had to say about losing two of his children:

I'll never forget my children's courage!

"It is, of cause every parent's worst fear to outlive their children. It is a violation of the natural rhythm of life. The deaths of our two children, Nelisuzulu and Mandisa, from HIV/AIDS within a few months of each other in 2004 left Irene, my children and me, numb with grief. Yet, we knew that this was not a singular time of bereavement. We were going through what millions of South Africans are experiencing.

My decision to speak about the cause of our children's death was difficult and personal. I felt I had a responsibility as a leader of my people to speak out against the stigma and silence, which are the main causes of the prolific spread of this deadly disease. I knew that I was taking a risk due to the sensitivities of such matters in the African culture. But I have never regretted it once. I hope my decision has made a small difference.

I did things that I would not countenance. For instance, I allowed myself to be filmed walking near my children's graves, for a British television station. I simply thought if the image helped, I should do so.

Dr Mangosuthu Buthelezi continues...

I personally, will never cease to campaign against the myth of "virgin cure", for education and empowerment of women, for improvement of court procedures for rape victims, and for assistance to orphans and child-headed households.

As for my dear children, I will never forget their doughty fight and their stubborn determination to live and, yes, smile in the most difficult times. The human spirit is really quite glorious-even in the shadow of death".

Source: Sunday Times News Paper, 28 $8^{\text {th }}$ May, 2006. 
In the same (Everyone Knows Someone) campaign by the Sunday Times News Paper, Former President of South Africa, Dr Nelson Mandela, had the following to say about the death of his son in 2002:

\begin{abstract}
I watched my son die"
My son died of AIDS IN 2002, aged 28.I am telling our story to underline the wide variations in HIVIAIDS causes and effects-and current advantages against it.

Andrew was gay and in 1982, we had discussed a terrifying illness reportedly emerging among young homosexual men in London where he lived. He had promised to take preventative measures with any partner.

In 1995 he learnt by chance, after a minor operation, that he was infected. The pathologist asked if he was homosexual, then said "Your blood test shows the HIV virus, which means you'll get cancer and Aids and you'll die. You people are society's scourge". There was no advise or counselling-just cruelty and misinformation. Andrew was only 21.

The worse was to come. The partner he trusted admitted to purposely infecting him because her own family had rejected her. Andrew reeled, but mustered his courage and vowed "to live until I die without harming anyone".

In the 80s in England he remained silent about his status to avoid losing his job and becoming a social pariah. His brother stood by him. Without any drugs generally available to combat the virus, Andrew relied on a healthy diet and gym. Above all, he lived with joyous zest for seven years. "I've lived 60 years in 28 - don't mourn that Ma".

The axe fell with shingles then a plunging CD4 cell count and eventually his entire nervous system failed. He died within seven months. I sat at his bedside, inspired and humbled by his indomitable spirit and wry humour.

Back in South Africa, I in turn remained silent. Denial or disgust was still 2002 society's response to AIDS and I didn't have the strength to fight back yet. I said he'd died of Leukaemia.

There are now enough enlightened people to defeat AIDS - but individually facing its honestly, responsibly and openly are the first essentials for that.
\end{abstract}

Source: Sunday Times Newspaper, $7^{\text {th }}$ May, 2006.

Judge Edwin Cameron who publicly declared his VIH-status had this to say: "I love being judge. The intellectual challenges are exhilarating ... but, I am also living with AIDS. I am still the public office bearer in South Africa to have chosen to make public my HIV-status. I felt I was called to witness. I felt called to account for my survival in a country in which hundreds of thousands were dying. I did not feel I should remain silent" (Cameron, 2005).

\title{
5. The Present Study
}

The study aimed to investigate the issues of disclosure in relation to HIV and AIDS. The research objectives were therefore as follows:

(a) To reveal to the public a conducive environment for disclosure.

(b) To establish the impact of disclosing one's HIV-positive status.

(c) To empower HIV-positive individuals to seek appropriate support and counselling.

\section{Research Methods}

The sample for the present study comprised of $30 \mathrm{HIV}$ - positive men and women belonging to the support groups that are based at one of the hospitals in KwaZulu- Natal. All participants in the study were aware of their HIV status, and had received post-test counselling, and had disclosed in their groups. However, some had not disclosed to family members or the community.

After informal contacts and conversations with officials at the research hospital, they were very receptive to the idea of research being conducted on HIV-positive individuals who belong to the support groups. The researcher was also afforded the opportunity to make informal contacts and conversations with leaders of the different support groups. Gaining the confidence of both hospital officials and support group leaders did not prove to be especially problematic. Good rapport was established with hospital officials and research participants. Care was taken to avoid the appearance of a close alignment with any individual or group over another. Gaining approval and acceptance of support groups, was vital to the success of the study. Thus, the researcher was able to select a sample of $\mathrm{N}=30$ (15 Males and 15Females). This sample was selected from a population of 133 HIV-positive support group members, who are unemployed, and stay in the local community. The random sampling procedure was used. This means that every support group member had an equal chance of being selected for the study.

Informed consent was obtained from the participants after the purpose of the study had been explained to them. From a population of 133 HIV-positive support group members, each member was assigned a number so that the 
researcher could not be biased by labels, names or any identifying criteria.

A master identification file was created that linked the numbers to names in order to later permit the correction of missing or contradictory information, and was kept by the researcher.

We used a questionnaire to solicit the necessary information on the issues of disclosure in relation to HIV and AIDS.

The questionnaire consisted of two sections: The biographical inventory and the individual needs exploratory section. Quantitative data was analysed using frequencies and percentages. Information narrated by the participants was summarized and categorized into themes.

\section{Results}

\subsection{Definition of disclosure}

When the participants were asked the question "how would you define disclosure?" two types of themes emerged. In the first theme which was reported by seventy percent (70\%) of the participants, $(65 \%)$ females and (5\%) males, defined disclosure as a positive act and considered sharing of emotions and HIV-related information as an important part of coping with the illness.

In the second theme which was reported by thirty percent (30\%) of the participants (25\%) females and (5\%) males, defined disclosure as an undesirable act but occurred because the individual felt that there was no other choice. Disclosure in the participants was accompanied by a sense of hopelessness.

\subsection{Reasons for disclosing one's HIV-positive status}

There were two themes that were revealed by the participant's response to the question, Seventy percent (70\%), of the participants reported that they had chosen to disclose to elicit different forms of support, which included both financial and emotional support. Fifteen percent (15\%) reported disclosing for financial support. Another (15\%) reported in order to gain medical care. A small percentage of (10\%) felt it was their responsibility since their partners needed testing.

This finding is supported by the social support theories who distinguish between three basic types of support, namely, Informal support which helps people stay grounded in the realities of their conditions.

Secondly, Emotional support which is offered through affection and empathy.

Thirdly, Tangible support which is important at the later stages of the disease when people need help such as, housekeeping, shopping, transport and other tasks of daily life.

\subsection{Reasons for not disclosing}

Concerning the reasons for not disclosing, all participants 30(100\%) overwhelmingly agreed that isolation, and social stigma that HIV-positive people experience are the reasons for not disclosing. Participants were asked to supply examples of "bad treatment" that they are faced with, (70\%) of male participants reported examples of social isolation, gossip(50\%), rejection from the home(33\%),rejection from the community(20\%), and verbal abuse (15\%). Female participants reported (65\%) social isolation, (40\%) rejection and discrimination, gossip (50\%) and verbal abuse (30\%). Nearly $60 \%$ percent of the sample reported fears related to society's attitudes towards the illness.

Disclosing of HIV infection can lead to important social support that can mitigate the negative effects of stress (Hays et al., 1993). Conversely, hiding one's status may not only preclude HIV -related social support and its attendant benefits but may also have direct negative effects of disease progression for HIV -positive individuals.

\subsection{Positive benefits obtained by disclosing}

It is interesting to note that some of the themes that emerged when the participants were asked the question: "What were the reasons for disclosing your HIV- positive status" also came up here. Eighty percent (80\%) of the participants reported receiving financial and emotional support as positive benefits that they obtained by disclosing the HIV-positive status. Twenty percent (20\%) reported that they received financial support from relatives and friends. Thirty percent (30\%) reported receiving emotional support and acceptance by members of the support group.

Disclosure of serostatus has implications for social support, which in turn, may affect psychological wellbeing. Disclosure or knowledge of serostatus has often been positively related to social support. 


\subsection{Negative effects of disclosing}

Regarding the negative effects resulting from disclosing one's HIV-positive status, fifteen percent(15\%) females and eighteen percent(18) males had already felt discriminated against by relatives. This proportion was similar for discrimination by friends, fifteen percent (15\%) females and eighteen percent (18\%) males, which was slightly higher for discrimination by sexual partners twenty-two percent(22\%) females and thirty six percent(36\%) males.

South Africa as with most other countries worldwide, has reported a large number of incidents of rejection and discrimination. These include the murder of Mpo Mtloung together with her mother by Mpo's husband, whom then also committed suicide.(Treatment Action Campaign, 2000), not allowing HIV-positive children into schools (SAPA,2002) exclusions or attempted exclusions from the workplace and in home communities (Gosling, 2000) and rejection from families.

Table 1: Circumstances under which disclosure occurred

\begin{tabular}{|l|c|c|}
\hline Types of Disclosure & Frequency & Percentage \\
\hline Voluntary with my consent & 18 & 60 \\
\hline Disclosure occurred without my consent & 7 & 23 \\
\hline Disclosure had to occur as there was no other choice & 5 & 17 \\
\hline
\end{tabular}

Table 1 revealed that $60 \%$ of the participants reported that disclosure occurred voluntarily with their consent. While $23 \%$ reported that disclosure occurred without the participant's consent only 17\% reported that disclosure had to occur as there was no other alternative.

Table 2: Persons to whom disclosure occurred

\begin{tabular}{|l|c|c|}
\hline & Frequency & Percentage \\
\hline Parents/siblings/spouse & 10 & 33 \\
\hline Relatives & 4 & 13 \\
\hline Professionals only & 8 & 27 \\
\hline Religious people only & 5 & 17 \\
\hline Neigbours & 4 & 13 \\
\hline Community & 4 & 13 \\
\hline Support groups & 7 & 23 \\
\hline
\end{tabular}

Table 2 shows that in 33\% of the participants' disclosure occurred to parents, siblings or spouse while $27 \%$ disclosed occurred to professionals only and $23 \%$ disclosed to support group members. While $17 \%$ disclosed to religious people and $13 \%$ disclosure occurred to relatives, such as cousins or uncles, as well as neighbours and community. It should be note here that the total percentage to whom disclosure occurred, adds up to more than $100 \%$ due to participants giving multiple responses.

\subsection{How do aspects of the support group environment differ from the home and community?}

With regard to listing of aspects in which the environment in the support groups differs from home and community, five key themes emerged. These are:

(i) "Gaining support from group members ..."

(ii) "Be empowered..."

(iii) "Love and acceptance...?

(iv) Healing places...?

(v) "Getting educated...?

\subsection{Gaining support from group members}

As opposed to the community and home environment, participants overwhelmingly felt that in the support groups they receive care and support from HIV-infected individuals. 
According to the participants, it is not only about HIV and AIDS because if you have the virus, you sometimes have other problems like, stress, isolation, and stigmatization.

\subsection{We need to be empowered}

All participants $(\mathrm{N}=30)$ expressed a need for different kinds of information. They also expressed the view that in the support groups they feel more useful, responsible and are empowered rather than to be frustrated by the community.

\subsection{Love and acceptance}

All participants $(\mathrm{N}=30)$ in this study expressed the view that the support group is a major source of love and acceptance. In the supports groups, participants reported that they benefit skills to deal with their issues, including their feelings, health concerns, changed social conditions and fear. Usually in support groups one gains acceptance, support, gets nurtured and intimacy from close friendship groups.

\subsection{Places of healing}

All participants $(\mathrm{N}=30)$ agreed that the environment in the support groups provide a relaxed place to share their life experiences and build new friendships. In support groups they learn that they are not alone and that they can still build a new life.

\subsection{Getting educated about HIV/AIDS}

The participants agreed that the provision of information including, being faithful to one's sexual partner , abstinence from sexual intercourse and the use of condoms as very essential. This type of information is not provided at home especially for the children, but received in the support groups. Research by Selvan,et al., (2001) revealed that when parents are better educated and informed, adolescents are less likely to be sexually active. This also confirms the findings of James and Glover (1993) who found that $92 \%$ of the participants in their study felt that AIDS education could successfully prevent the spread of AIDS.

\section{Conclusion}

This study has shown that Disclosure of one's HIV-positive status is an important public health goal for a number of reasons. For example, disclosure may motivate sexual partners to seek testing, change their behaviour, and decrease the levels of community discrimination and stigmatization as well as eradication of myths about HIVIAIDS. In light of the findings of the study, the researcher was able to establish an intervention programme aimed at addressing the common barriers associated with HIV disclosure.

\section{Recommendations}

Government needs to invest more money in HIVIAIDS research and training programmes for HIVIAIDS counsellors, medical doctors, traditional healers and communities at large.

More research needs to be done in order to give support to people who are HIV-negative to address and alleviate their fears which may be interpreted as discrimination.

\section{References}

Armistead, L. and Tanebaum, L. (2001). Disclosing HIV status: are Mothers telling their Children? New York: Plenum Books.

Butler AM, Williams PL, Howland LC, Storm D, Hutton N, Seage GR 3rd, Team (2009) Impact of disclosure of HIV infection on healthrelated quality of life among children and adolescents with HIV infection. Pediatrics, 123(3): 935-43.

Cameron, E. (2005). Witness to AIDS. Cape Town: Tafelberg Publishers Ltd.

Darelga, V.J., WInstead, B.A. and Barron, L. (2001). Reasons for and against disclosing HIV positive test results. New Bury Park, CA: SAGE.

Duffy, V.J. (1994). Crisis points in HIV disease. Journal of AIDS patient Care, 8(2): 28-32.

Ewing, P. (2003). Coping with marginalization in the context of HIVIAIDS: Report of the National Summit, Durban, South Africa. 7-8 
August. GAF/ICW.

Ferris M, Burau K, Schweitzer AM, Mihale S, Murray N, et al. (2007) The influence of disclosure of HIV diagnosis on time to disease progression in a cohort of Romanian children and teens. AIDS Care, 19(9): 1088-94.

Gideon, M. 2005. Living With Aids. Available @ http://ngm.nationalgeographic.com/ngm/0509/feature4/

Gosling, M. (2000). Bad turnout for positive, providers and prejudice. Cape Times p. 3, (20 june).

Grubman S, Gross E, Lerner-Weiss N, et al. (1995). Older children and adolescents living with perinatally acquired human immunodeficiency virus infection. Pediatrics, 95: 657-663.

Hays, R.B., Mukusick, L, Pollack,L., Hoff, C. and Coates, T.J. (1993). Disclosing HIV seropositivity to significant others. AIDS, 7, 425431. http//www.avert.org/origins.htm

James, C.P. and Glover, P.H. (1993). Aids education inschols: awareness attitudes and opinions among educators, theology students and health professional. South African Medical Journal, 83, 675-679.

Kirshenbaum SB, Nevid J. (2002). The specificity of maternal disclosure of HIVIAIDS in relation to children's adjustment. AIDS Educ Prev, 14:1-16.

Lesch A, Swartz L, Kagee A, Moodley K, Kafaar Z, et al. (2007) Paediatric HIVIAIDS disclosure: towards a Developmental and processoriented approach. AIDS care 19(6): 811-816.

Murphy DA, Steers WN, Stritto ME (2001) Maternal disclosure of mothers' HIV serostatus to their young children. Journal of Family Psychology, 15: 441-450.

SAPA (2002). Nursery schools that refused HIV child in court oday. Cape Times, (13 June).

Selvan, M.S., Ross, M.W. and Kapadia, A.S. (2001). Study of perceived norms, beliefs and intended sexual behaviour among secondary school students in India. AID care, 13.

Sunday Times Newspaper, 28 May (2006)

Sunday Times Newspaper, 7 May, (2006)

Treatment Action Campaign (TAC), (2000). "Mourn Mpho Motloung! Change HIVIAIDS Message to show Hope now! False message increase violence against women".

World Health Organization and UNICEF (2008) Scale up of HIV-related prevention, diagnosis, care and treatment for infants and children: A Programming Framework. Geneva,

World Health Organization and UNICEF (available@http://www.who.int/hiv/pub/paediatric/paediatric_programme_fmwk2008.pdf. Accessed 05 June 2009).

UNAIDS Global AIDS epidemic update report (2010). Geneva, UNAIDS, (available@http://www.unaids.org/en/KnowledgeCentre /HIVData/GlobalReport/2008/2010_Global_report.asp.

Van Wyk, A.C. (1999). Aids care and counselling. Cape Town: Masker Miller Logman.

Wolfe, N.D., Switzer, W.M., Carr, J.K. (2004). "Naturally acquired Simian retrovirus infections in Central African Hinters". The Lancelot, 369: 932. 